\title{
Radical Copolymerization Behavior of Macromonomers; Incompatibility Effect
}

\author{
Yasuhisa Tsukahara, ${ }^{*}$ Noriyuki HaYAShI, Xiu-Lan JiAnG, \\ and Yuya YAMASHITA
}

Department of Synthetic Chemistry, Faculty of Engineering,

Nagoya University, Nagoya 464, Japan

(Received November 20, 1988)

\begin{abstract}
Copolymerizations of methacrylate terminated styrene macromonomer (MSt, $M_{n}=12400$ ) and dimethylsiloxane macromonomers (MDMS, $M_{n}=1020,8670$ ) with methyl methacrylate (MMA) were investigated in benzene (Bz), cyclohexane ( $\mathrm{Ch}$ ), and phenetol (Pht) to clarify the incompatibility effect between the macromonomer and the propagating comonomer chain on copolymerization behavior of the macromonomers. In the $\mathrm{MSt} / \mathrm{MMA} / \mathrm{Bz}$ copolymerization system i.e., copolymerization in mutual good solvent, it was observed that the relative copolymerization reactivity of macromonomer is almost the same as that of the small monomer corresponding to the polymerizable end group under homogeneous solution reaction conditions. On the other hand, in the MDMS/MMA/Bz copolymerization system, decrease in the reactivity of macromonomer was observed even under homogeneous solution conditions. These results were considered in terms of differences in the degree of interpenetration of unlike polymers in the reaction medium due to the different effects of incompatibility between the macromonomer and the propagating comonomer chain. Furthermore, in the case of copolymerizations in a preferential solvent, MSt/MMA/Ch and MDMS/MMA/Pht systems, the copolymerization system became heterogeneous as copolymerization proceeded and polymer particles of considerably uniform size were produced due to stabilization by the graft copolymers produced. In these cases, appreciable decrease in the relative copolymerization reactivity of macromonomer was observed due to much decrease in the interpenetration of unlike polymer species.
\end{abstract}

KEY WORDS Macromonomer / Copolymerization / Monomer Reactivity Ratio / Thermodynamic Repulsive Interaction / Interpenetration of Unlike Polymers /

Contrary to the traditional point of view on a monomer unit as the basic unit, in polymer material designs, many workers have recently begun to regard the oligomer or polymer as the basic unit, functional unit or reaction unit. Recent increased study on the synthesis and copolymerization of macromonomers as well in the material design is understandably in line also with this thought. ${ }^{1-11}$ It has been also well recognized that the macromonomer method is a very useful and important synthetic route of various kinds of well-defined graft copolymers by which the number and length of branch segments can be well controlled. However, the copolymerization behavior of a macromonomer as well as the homopolymerization behavior is not well understood at present. $^{12-19}$

Ito et al. ${ }^{12,13}$ recently studied the radical copolymerization reactivity of poly(ethylene oxide) macromonomers, the terminal groups of which were methacrylate and vinylbenzyl groups, with styrene comonomer and found that the reactivity of macromonomers was

\footnotetext{
* To whom correspondence should be addressed.
} 
molecular weight dependent. The higher the molecular weight of a macromonomer, the lower became the copolymerization reactivity, and the reactivity was appreciably lower than small monomer homologues in a high molecular weight region. Cameron and $\mathrm{Chisholm}^{14}$ also reported similar results, i.e., the higher the molecular weight, the lower the copolymerization reactivity of the macromonomer, with the copolymerization system of poly(dimethylsiloxane) macromonomer having a methacrylate end group with styrene and acrylonitrile. On the other hand, Schulz and Milkovich ${ }^{15}$ reported the same or slightly lower reactivity of macromonomers compared with the small monomer corresponding to the polymerizable end group in the copolymerization system of methacrylate-terminated polystyrene macromonomers. There are also other reports showing that the copolymerization reactivity of a macromonomer is not so different from that of a small monomer corresponding to the polymerizable end group even with a molecular weight of macromonomer as high as ten thousands. ${ }^{16-18}$

On the copolymerization reactivity of a macromonomer, the following can be considered as major influencing factors: i) copolymerization reactivity of the polymerizable end group associated with the chemical structure of the end group, ii) enhanced diffusion control effect associated with the large size of a macromonomer. This might reduce the relative propagation rate of the macromonomer to the small comonomer, since the large molecular weight of the macromonomer might reduce its translational diffusivity and increase the topological resistance against the segmental diffusion of the reactive end group. ${ }^{19-29}$ iii) non-homogeneous distribution of the polymerizable end group in the reaction media associated with the thermodynamic repulsive interaction between a macromonomer and a propagating comonomer chain and/or incompatibility between unlike polymers. ${ }^{29-35}$

In this paper, we studied the radical copo- lymerization behavior of styrene and dimethylsiloxane macromonomers with MMA comonomer to elucidate the effects of the thermodynamic repulsive interactions between the polymer reaction species on copolymerization behavior. The results obtained are discussed in terms of the interpenetration of macromonomer coils and unlike propagating comonomers chains in the reaction media.

\section{EXPERIMENTAL}

\section{Materials}

Methyl methacrylate and styrene (St) monomers, azobisisobutyronitrile (AIBN), benzene, cyclohexane, phenetol, and other solvents were obtained commercially. Monomers and solvents were dried and distilled under nitrogen atmosphere. St monomer and benzene used in the living anionic polymerization were further purified with the sodium salt of benzophenone several times under high vacuum.

\section{Macromonomers}

St macromonomer (MSt) with narrow molecular weight distribution having a methacrylate end group was prepared by the living anionic polymerization of $\mathrm{St}$ in $\mathrm{Bz}$ followed by the reaction of ethylene oxide and methacrylate chloride according to Shultz and Milkovich. Dimethylsiloxane macromonomers, (MDMS) also prepared by living anion polymerization, were kindly supplied by Chisso Co., Ltd., Japan. The preparation procedures of these macromonomers are shown in Scheme 1. The content of the methacrylate end group in the macromonomers was estimated by UV, IR, NMR and the maximum conversion of macromonomers in the copolymerizations with MMA in Bz. Molecular weights of macromonomers were determined by Gel Permeation Chromatography (GPC) with HLC802 of Tosoh (Toyo Soda) Co., Ltd. and Vapor Pressure Osmometry (VPO) with 115 of Corona Electric Co. The molecular weights 


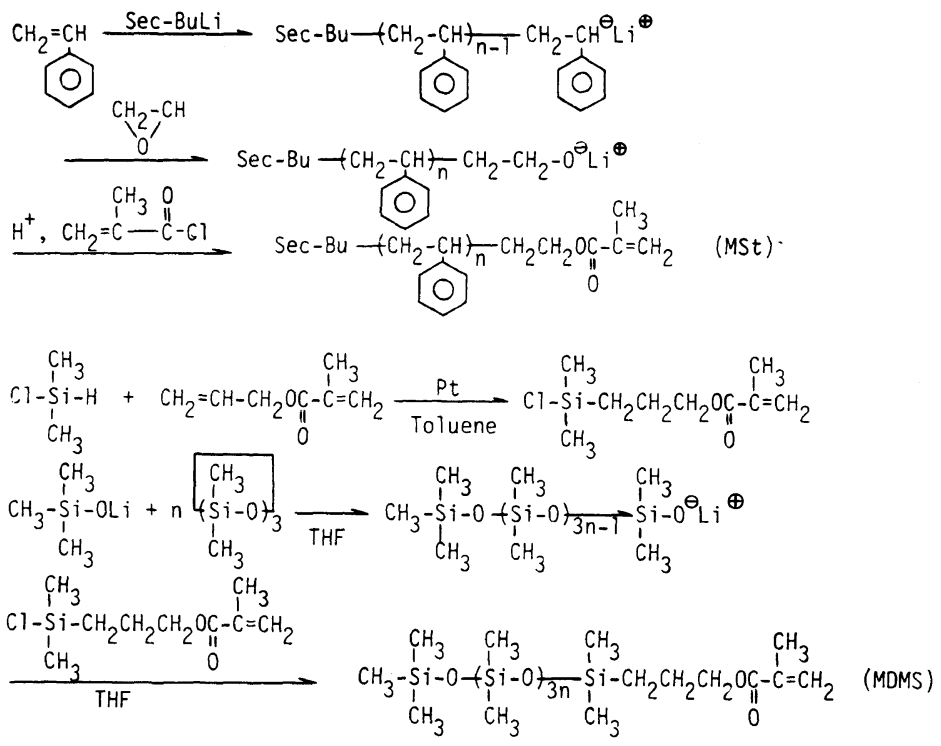

Scheme 1.

Table I. Macromonomers

\begin{tabular}{lrrrrr}
\hline \multicolumn{1}{c}{ Code } & $M_{n}$ & $M_{w}$ & $M_{w} / M_{n}$ & $D_{\mathrm{p}}{ }^{\mathrm{a}}$ & $f^{\mathrm{b}}$ \\
\hline MST & 12400 & 13100 & 1.06 & 122 & 0.86 \\
MDMS-1 & 1020 & 1140 & 1.12 & 11 & $\simeq 1.00$ \\
MDMS-3 & 8670 & 10750 & 1.24 & 143 & $\simeq 1.00$ \\
\hline
\end{tabular}

a Based on $M_{n}$.

b End functionality determined from UV and IR spectra.

were calculated by using calibration curve of Tosoh PSt standard samples, and are shown in Table I together with the end group functionality.

\section{Copolymerization}

Radical copolymerization of macromonomers with MMA comonomer was carried out with AIBN as an initiator and in a copolymerization solvent in glass ampules and sealed under vacuum at $60^{\circ} \mathrm{C}$. MSt was copolymerized in $\mathrm{Bz}$ and $\mathrm{Ch}$, whereas MDMSs were copolymerized in $\mathrm{Bz}$ and $\mathrm{Pht} . \mathrm{Bz}$ is a good solvent for all poly(methyl methacrylate) (PMMA), polystyrene (PSt), and poly(dimethyl siloxane) (PDMS), whereas $\mathrm{Ch}$ and
Pht are preferential solvents. The former is a poor solvent for PMMA and the latter is a poor solvent for PDMS (theta-temperature of Pht for PDMS is reported $83^{\circ} \mathrm{C}$ by Flory ${ }^{38}$ and $89^{\circ} \mathrm{C}$ by Kuwahara ${ }^{39}$ ). The segregation factor between MSt and PMMA is rather weak, while strong between MDMS and PMMA. ${ }^{40}$ The prepared homogeneous (transparent) mixture of the macromonomer, comonomer, initiator and solvent was equally divided into eight parts and copolymerized in glass ampules under vacuum for various copolymerization times to get time-conversion data. Feed macromonomer compositions were fixed at $50 \mathrm{wt} \%$ in all cases. Total monomer concentrations in the copolymerizations in $\mathrm{Bz}$ were chosen as high as possible under the restriction of a homogeneous solution condition, above which the reaction mixture became opaque as the copolymerization proceeded due to the phase separation. Copolymerization in selective solvent was done under the same conditions as in $\mathrm{Bz}$ for comparison. Copolymerization conditions of MDMS-1 were almost the same as those of MDMS-3. Details of the copolymerization conditions are shown in Table II. 
Table II. Copolymerization conditions of macromonomers

\begin{tabular}{|c|c|c|c|c|c|c|c|c|c|}
\hline \multirow{2}{*}{ Code } & \multirow{2}{*}{ Solvent } & \multirow{2}{*}{$\begin{array}{c}\begin{array}{c}\text { Macro- } \\
\text { monomer }\end{array} \\
\text { mmol }\end{array}$} & \multirow{2}{*}{$\frac{\text { Comonomer }}{\mathrm{mmol}}$} & \multicolumn{2}{|c|}{$\begin{array}{l}\text { Composition of } \\
\text { macromonomer }\end{array}$} & \multirow{2}{*}{$\begin{array}{c}\text { AIBN } \\
\mathrm{mmol}\end{array}$} & \multirow{2}{*}{$\frac{\text { Solvent }}{\mathrm{ml}}$} & \multicolumn{2}{|c|}{$\begin{array}{c}\text { Total monomer } \\
\text { concentration }\end{array}$} \\
\hline & & & & $\mathrm{mol} \%$ & $\mathrm{wt} \%$ & & & $\mathrm{moll}^{-1}$ & $\mathrm{~g} \mathrm{ml}^{-1}$ \\
\hline \multirow[t]{2}{*}{ MSt } & Benzene & 0.00897 & 1.12 & 0.795 & 49.8 & 0.007 & 0.72 & 1.57 & 0.310 \\
\hline & Cyclohexane & 0.0806 & 10.0 & 0.800 & 50.0 & 0.061 & 6.0 & 1.68 & 0.333 \\
\hline \multirow[t]{2}{*}{ MDMS-1 } & Benzene & 0.464 & 4.89 & 8.67 & 49.2 & 0.036 & 4.0 & 1.34 & 0.241 \\
\hline & Phenetol & 0.410 & 4.22 & 8.86 & 49.8 & 0.029 & 4.0 & 1.58 & 0.210 \\
\hline \multirow[t]{2}{*}{ MDMS-3 } & Benzene & 0.0573 & 5.08 & 1.12 & 49.4 & 0.035 & 4.0 & 1.28 & 0.251 \\
\hline & Phenetol & 0.0472 & 4.08 & 1.14 & 50.1 & 0.031 & 4.0 & 1.03 & 0.204 \\
\hline
\end{tabular}

Copolymerizations were carried out in degassed glass ampules at $60^{\circ} \mathrm{C}$.

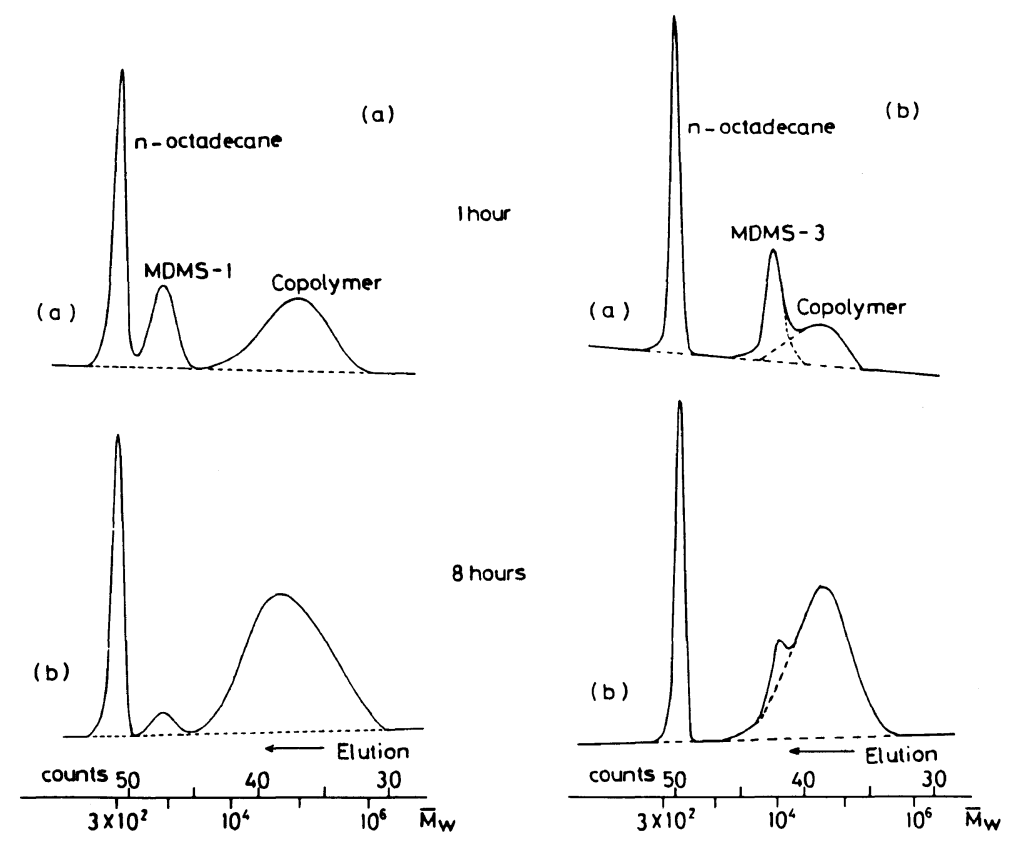

Figure 1. Typical GPC charts of the copolymerization products of (a) MDMS-1 and (b) MDMS-3 with MMA. Copolymerization time is $1 \mathrm{~h}$ (upper charts) and $8 \mathrm{~h}$ (lower charts).

Conversions of macromonomers were determined from GPC, which were taken with Tosoh G6000H-G4000H-G2000H columns operated at $40^{\circ} \mathrm{C}$ on THF and chloroform with a solvent flow rate of $1.2 \mathrm{ml} \mathrm{min}^{-1}$. The concentration of the sample injection was 0.2 $\mathrm{mg} \mathrm{ml}^{-1}$ and the by-pass injection loop is 0.5 $\mathrm{ml}$. Conversions of macromonomer at given copolymerization times were determined from the relative peak area of unreacted macro- monomer to that of $n$-octadecane peak as an internal standard using calibration curves. The typical GPC curves of the copolymerization products in the case of DMS macromonomer systems are shown in Figure 1. The decrease of the relative peak area of the unreacted macromonomers to the $n$-octadecane peak with reaction time can be determined from the figure. Conversions of comonomer were determined by both Gas Chromatography (GC) using 
Yanaco G2800. The weight change of the copolymerization product after complete removal of the unreacted MMA comonomer by freeze drying with $\mathrm{Bz}$ was also measured. In the case of the PSt macromonomer, correction for the end group functionality was done using $f=0.86$ for the calculation of the monomer reactivity ratios.

\section{RESULTS AND DISCUSSION}

\section{Evaluation of Copolymerization Reactivity of \\ Macromonomers}

Copolymerization behavior of monomer-1 $\left(M_{1}\right)$ and monomer $\left(M_{2}\right)$ are usually discussed on the basis of the well-known copolymerization equation with data at very low degrees of conversion such that the feed composition is negligibly unchanged from its initial value, ${ }^{41}$

$$
\frac{\mathrm{d}\left[\mathrm{M}_{1}\right]}{\mathrm{d}\left[\mathrm{M}_{2}\right]}=\frac{\left[\mathrm{M}_{1}\right]\left(r_{1}\left[\mathrm{M}_{1}\right]+\left[\mathrm{M}_{2}\right]\right)}{\left[\mathrm{M}_{2}\right]\left(r_{2}\left[\mathrm{M}_{2}\right]+\left[\mathrm{M}_{1}\right]\right)}
$$

where $\left[\mathrm{M}_{1}\right]$ and $\left[\mathrm{M}_{2}\right]$ are the molar concentrations of $M_{1}$ and $M_{2}$, and $r_{1}$ and $r_{2}$ are the respective monomer reactivity ratios. However, understanding of copolymerization behavior of macromonomers including high degrees of the conversion region is also important in the preparation of graft copolymers for practical use. In this study, we evaluated the radical copolymerization behavior of macromonomers using the Skeist method, where the experimental times versus conversion data were fitted to the calculated instantaneous feed composition-degree of conversion curves of different $r_{1}$ and $r_{2} \cdot{ }^{42-44}$ In this method, the relation between conversion and instantaneous feed compositions of $M_{1}$ and $M_{2}$, and $f_{1}$ and $f_{2}$, is given by the following equation,

$$
\begin{aligned}
X & =1-\frac{[\mathrm{M}]}{[\mathrm{M}]_{0}} \\
& =1-\left[\frac{f_{1}}{\left(f_{1}\right)_{0}}\right]^{\alpha}\left[\frac{f_{2}}{\left(f_{2}\right)_{0}}\right]^{\beta}\left[\frac{\left(f_{1}\right)_{0}-\delta}{f_{1}-\delta}\right]^{\gamma}
\end{aligned}
$$$$
\text { (for } r_{1} \neq 1.0, r_{2} \neq 1 \text {.0) }
$$

Polymer J., Vol. 21, No. 5, 1989 where $f_{1}$ and $f_{2}$ are the instantaneous feed composition (mole fraction) of $M_{1}$ and $M_{2}$, $\left(f_{1}\right)_{\mathrm{o}}$ and $\left(f_{2}\right)_{\mathrm{o}}$ are their initial values. [M] is the total monomer concentration $\left([\mathrm{M}]=\left[\mathrm{M}_{1}\right]+\right.$ $\left.\left[\mathrm{M}_{2}\right]\right)$ and $[\mathrm{M}]_{\mathrm{o}}$ is its initial value. $\alpha, \beta, \gamma, \delta$ are given by

$$
\begin{aligned}
& \alpha=\frac{r_{2}}{\left(1-r_{2}\right)}, \quad \beta=\frac{r_{1}}{\left(1-r_{1}\right)} \\
& \gamma=\frac{\left(1-r_{1} r_{2}\right)}{\left(1-r_{1}\right)\left(1-r_{2}\right)}, \quad \delta=\frac{\left(1-r_{2}\right)}{\left(2-r_{1}-r_{2}\right)}
\end{aligned}
$$

When $r_{1} \neq 1, r_{2}=1$, the relation corresponding to eq 2 is given by

$$
\begin{aligned}
\ln \frac{[\mathrm{M}]}{[\mathrm{M}]_{0}}= & \ln \left[\left(\frac{f_{1}}{\left(f_{1}\right)_{0}}\right)^{1 /\left(r_{1}-1\right)}\left(\frac{\left(f_{1}\right)_{0}-1}{f_{1}-1}\right)^{1 /\left(r_{1}-1\right)}\right] \\
& +\frac{1}{r_{1}-1}\left(\frac{1}{\left(f_{1}\right)_{0}}-\frac{1}{f_{1}}\right)
\end{aligned}
$$

In the above equations, $f_{1}$ and $f_{2}$ at conversion $X$ were determined by GPC and GC, as described in the experimental section.

When $M_{1}$ is the comonomer and $M_{2}$ is the macromonomer, the relative copolymerization reactivity of macromonomer is normally evaluated by $1 / r_{1}$, i.e., the rate constant for a propagating comonomer radical adding macromonomer to the rate constant for its own comonomer, because the feed composition of the macromonomer in moles is extremely low even at high feed composition by weight in an ordinary system, which makes it difficult to determine the exact value of $r_{2}$ directly.

Since the macromonomers in this study had an MMA group at each chain end and were copolymerized with MMA comonomer, the macromonomer can be expected to be copolymerized in an ideally random manner, if the copolymerization reactivity of the end group is the predominant factor in determining the copolymerization behavior of the macromonomers. Hence, the copolymerization should be azeotropic, i.e., the monomer reactivity ratios are $r_{1}=r_{2}=1.0$. In other words, when there exists some incompatibility effect or a 
diffusion control effect, the copolymerization will deviate from the azeotropic behavior. This deviation can be easily seen by examination of the instantaneous feed composition variation with the degree of conversion using eqs 2 and 3 in the following discussion.

\section{Copolymerization Behavior of St-Macro- monomer with MMA}

Results of copolymerization of MSt with MMA in $\mathrm{Bz}\left(C^{\mathrm{t}}\right.$, the initial total monomer concentration in $\mathrm{g} \mathrm{ml}^{-1}$, is 0.310 ) are shown in Table III, together with the copolymerization data in $\mathrm{Ch}\left(C^{\mathrm{t}}=0.333 \mathrm{~g} \mathrm{ml}^{-1}\right)$. Obtained timeconversion curves of the macromonomer and comonomer are shown in Figure 2. The copolymerization system in $\mathrm{Bz}$ at this $C^{\mathrm{t}}$ was transparent through the copolymerization reaction $(48 \mathrm{~h})$, while in $\mathrm{Ch}$, the reaction mixture be- came gradually turbid from the initial stage and finally opaque.

It is seen from Table III that the instantaneous feed compositions of $\mathrm{MSt}$ in $\mathrm{Bz}$ are almost the same as the feed value during the copolymerization. Furthermore, the compositions of the produced graft copolymers are almost the same as the feed value and do not change much as the copolymerization proceeds. On the other hand, the instantaneous feed composition of MSt in $\mathrm{Ch}$ increases with reaction time because of the increase in the amount of unreacted macromonomers. Accordingly, the compositions of macromonomer in the copolymerization products are lower than the feed composition.

Molecular weights of the copolymerization products in $\mathrm{Bz}$ are about $4-5 \times 10^{4}$, while those in $\mathrm{Ch}$ are more than $10 \times 10^{4}$ and much

Table III. Comparison of copolymerization behavior of macromonomer with MMA in benzene and cyclohexane ${ }^{a}$

\begin{tabular}{|c|c|c|c|c|c|c|}
\hline \multirow{2}{*}{$\frac{\begin{array}{c}\text { React. } \\
\text { time }\end{array}}{\mathrm{h}}$} & \multirow{2}{*}{$\begin{array}{c}\begin{array}{c}\text { Total } \\
\text { conv. }\end{array} \\
\mathrm{mol} \%\end{array}$} & \multicolumn{2}{|c|}{ MSt in feed } & \multicolumn{3}{|c|}{ Copolymz. product ${ }^{\mathrm{b}}$} \\
\hline & & $\mathrm{mol}^{\%} \%$ & $\mathrm{wt} \%$ & $\begin{array}{l}\text { MSt } \\
w^{\circ} \%\end{array}$ & $N_{\mathrm{b}}$ & $\begin{array}{c}M_{n} \\
\times 10^{-3}\end{array}$ \\
\hline \multicolumn{7}{|c|}{ Benzene } \\
\hline 1 & 8.6 & $0.785(0.677)$ & $49.5(45.8)$ & 53.3 & 1.8 & 41.2 \\
\hline 3 & 22.9 & $0.772(0.664)$ & $49.1(45.3)$ & 52.4 & 1.9 & 45.2 \\
\hline 5 & 37.1 & $0.813(0.700)$ & $50.4(46.6)$ & 49.0 & 2.0 & 50.4 \\
\hline 8 & 42.5 & $0.768(0.660)$ & $49.0(45.2)$ & 51.2 & 2.3 & 54.7 \\
\hline 13 & 70.2 & $1.042(0.896)$ & $56.6(52.9)$ & 46.5 & 1.6 & 42.0 \\
\hline 20 & 76.2 & $0.740(0.646)$ & $48.0(44.3)$ & 50.6 & 1.9 & 47.3 \\
\hline 30 & 84.4 & $1.305(1.122)$ & $62.1(58.6)$ & 46.8 & 1.8 & 46.9 \\
\hline 48 & 96.4 & $0.443(0.381)$ & $35.6(32.3)$ & 50.4 & 1.9 & 46.4 \\
\hline \multicolumn{7}{|c|}{ Cyclohexane } \\
\hline 0.3 & 7.0 & $0.801(0.689)$ & $50.0(46.1)$ & 49.7 & - & - \\
\hline 0.7 & 30.7 & $0.878(0.755)$ & $52.3(48.6)$ & 44.0 & - & - \\
\hline 1 & 45.2 & $1.116(0.960)$ & $58.3(54.5)$ & 33.8 & 5.5 & 200.0 \\
\hline 2 & 66.2 & $1.298(1.116)$ & $62.0(58.3)$ & 40.2 & 5.8 & 180.0 \\
\hline 4 & 74.6 & $1.535(1.320)$ & $65.9(62.2)$ & 40.7 & 7.9 & 240.0 \\
\hline 6 & 90.1 & $4.087(3.515)$ & $84.1(81.9)$ & 41.1 & 5.3 & 160.0 \\
\hline 9 & 93.3 & $2.440(2.098)$ & $75.6(72.3)$ & 43.6 & 3.9 & 110.0 \\
\hline 12 & 99.1 & $10.760(9.254)$ & $96.4(96.2)$ & 39.8 & - & - \\
\hline
\end{tabular}

${ }^{\text {a }}$ Initial feed ratio of macromonomer and comonomer is 1.0 by weight and $0.0081(0.0070)$ by mol. The values in the parentheses are corrected by the end functionality. Initial total monomer concentration is $0.333 \mathrm{~g} \mathrm{ml}^{-1}$ (solvent fraction $=0.75$ ).

b MSt, macromonomer; $N_{\mathrm{b}}$, number of graft segments per molecule. 


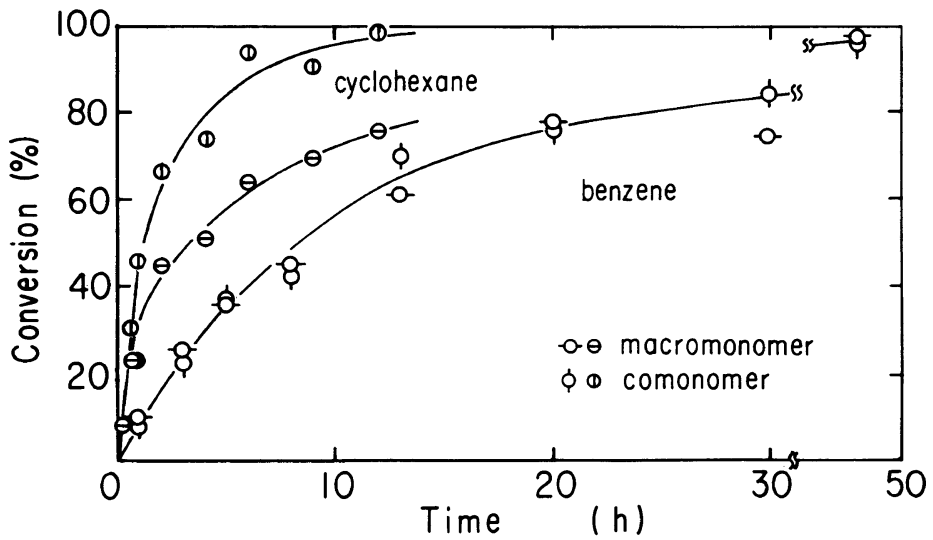

Figure 2. Time-conversion curves of the styrene macromonomer (MSt) and MMA comonomer in the copolymerization with benzene and cyclohexane. Copolymerizations were carried out with AIBN at $60^{\circ} \mathrm{C}$. The details of copolymerization conditions are shown in Table II.

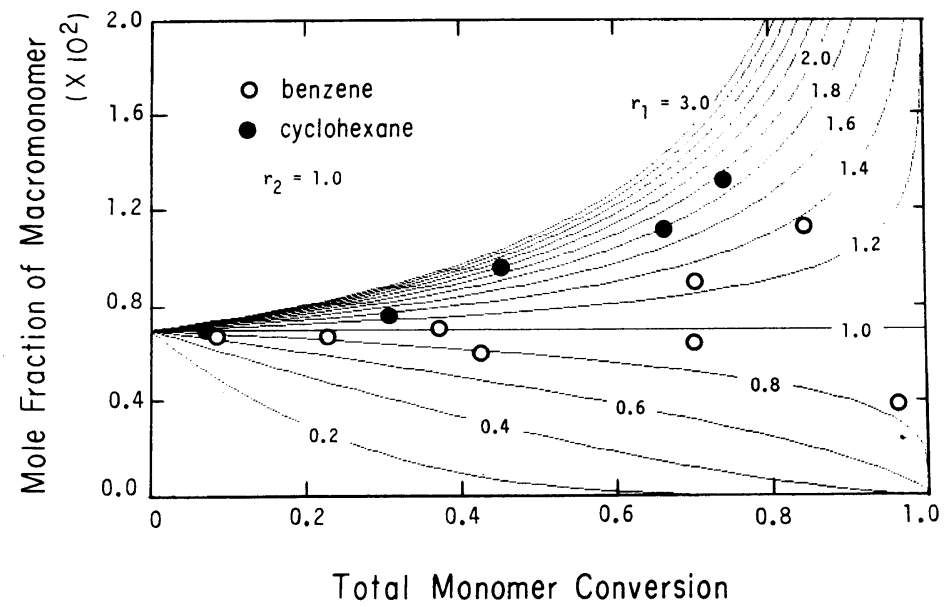

Figure 3. Plots of the experimental instantaneous mol fraction of MSt on calculated instantaneous mol fraction versus total monomer conversion curves. Curves in the figure were calculated with $r_{2}=1.0$ by using eq 3 .

larger than the values in Bz. It is seen in Figure 2 that the time-conversion curve of MSt in $\mathrm{Bz}$ is almost the same as that of MMA comonomer, while in $\mathrm{Ch}$, the rate of consumption of MSt is considerably slower than that of comonomer. However, the copolymerization rate itself in $\mathrm{Ch}$ is larger than that in $\mathrm{Bz}$.

These results were analyzed by Skeist's method to evaluate the copolymerization reactivity of the macromonomer with $1 / r_{1}$ value. Figure 3 shows plots of the copolymerization data on the calculated instantaneous macromonomer mole fraction versus total monomer conversion curves using eq 3 with $r_{2}=1.0$. Here, $r_{1}=r_{2}=1.0$ can be considered as the reference where the diffusion-controlled effect or the size effect is absent and only the copolymerization reactivity of the polymerizable end group is dominant. Since the mole fraction of MSt in the feed is much less than that of MMA (ca. 1/124), the calculated curves are not much dependent on the $r_{2}$ value. For in- 
stance, they are almost identical to those calculated from eq 2 with $r_{1}=0.5$, or 1.5 . It is seen from the figure that the experimental data in $\mathrm{Bz}$ system is scattered around the $r_{1}=$ 1.0 line, while the data in $\mathrm{Ch}$ deviate from the $r_{1}=1.0$ line and seem to increase with conversion. In other words, the copolymerization reactivity of $\mathrm{MSt}$ in $\mathrm{Bz}$ evaluated from $1 / r_{1}$ is almost the same as that of the small monomer corresponding to the polymerizable end group. This means that the MSt chain should extensively interpenetrate the coil of the propagating comonomer radical to make the distribution of the polymerizable end group homogeneous through the reaction media. Furthermore, the diffusion control effect expected from the large size of macromonomer is minor and negligible in this copolymerization system. On the other hand, it is seen from the figure that the apparent reactivity of MSt in $\mathrm{Ch}$ is clearly reduced compared with the corresponding small monomer.
The reaction mixture in $\mathrm{Ch}$ became turbid and heterogeneous during the copolymerization because of the precipitation of the PMMA component in $\mathrm{Ch}$ as mentioned before. Electron microscopy (EM) photographs of the copolymerization product are shown in Figure 4. The EM samples were prepared by dilution of the copolymerization product with $\mathrm{Ch}$ and cast on the mesh for EM. It is seen in Figure 4 that the fine particles of diameter $c a .0 .1$ $\mu \mathrm{m}$ are formed from the initial stage of the copolymerization. The size of these particles are considerably regular presumably due to the stabilization effect of the polystyrene segments of produced graft copolymers, which bear resemblance to the dispersion polymerization system described by Barrett et al. ${ }^{45}$ In such a case, the copolymerization reaction occurs at the interface of the particle as well as the diluent phase. The local concentration of the polymerizable end group of MSt around the propagating radical sites at interphase might be less than the overall

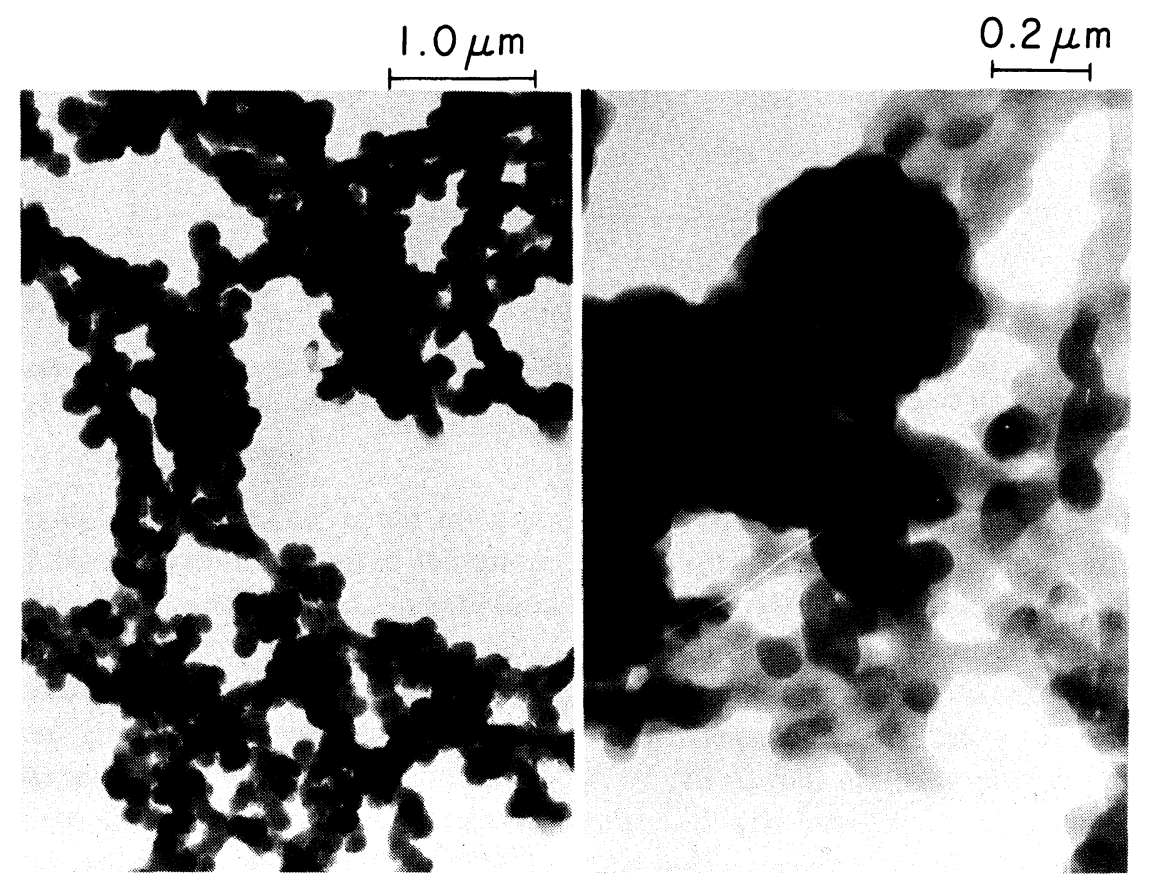

Figure 4. Electron micrograph of the copolymerization product of MSt/MMA/Bz copolymerization system. Copolymerization time was $1 \mathrm{~h}$. Other conditions are shown in Table II. 
concentration of the system, since the MSt chain cannot penetrate the PMMA particles. This might be partial reason for the observed reduction of reactivity of MSt in $\mathrm{Ch}$.

\section{Copolymerization Behavior of DMS-Macro- monomers with MMA}

Copolymerization data of MDMS-1 and MDMS-3 with MMA in $\mathrm{Bz}$ and $\mathrm{Pht}$ at $24 \mathrm{~h}$ are shown in Table IV, and the details of copolymerization data in the case of MDMS-3 in $\mathrm{Bz}$ are shown in Table $\mathrm{V}$. In regard to the conversion of macromonomers, it is more than $80 \%$ in case of MDMS- 1 and more than $70 \%$ in case of MDMS-3 at $24 \mathrm{~h}$. These values increased further at $48 \mathrm{~h}$, which is good indication of the high end functionality of each macromonomer.
In the case of MDMS-1, the $M_{n}$ of which is 1020 , the copolymerization mixtures are transparent and homogeneous in both $\mathrm{Bz}$ and $\mathrm{Pht}$ because of the low molecular weight of MDMS-1. It was found that the instantaneous feed compositions of MDMS-1 did not much depend upon the conversion and were almost the same as the initial feed composition in both $\mathrm{Bz}$ and Pht. Accordingly, the composition of the copolymerization product was almost the same as that of initial feed composition. $M_{w}$ of the copolymerization products in $\mathrm{Bz}$ was almost the same as those in Pht. The molecular weight distribution became broader as conversion proceeded. Figure 5 shows plots of the copolymerization data of MDMS-1 system in both $\mathrm{Bz}$ and $\mathrm{Pht}$ on the calculated instantaneous mole fraction versus total monomer

Table IV. Copolymerization of MDMS with MMA in benzene and phenetol ${ }^{\mathrm{a}}$

\begin{tabular}{|c|c|c|c|c|c|c|c|c|c|}
\hline \multirow{2}{*}{$\begin{array}{l}\text { Macromo- } \\
\text { monomer }\end{array}$} & \multirow{2}{*}{ Solvent } & \multicolumn{2}{|c|}{ Conversion $/ \%$} & \multicolumn{2}{|c|}{$\mathrm{MDMS}^{\mathbf{b}}$} & \multicolumn{4}{|c|}{ Copolymerization product } \\
\hline & & MDMS & MMA & $\mathrm{mol}_{\%}^{\mathrm{o}}$ & $\mathrm{wt} \%$ & MDMS (wt $\%)$ & $M_{w}\left(10^{4}\right)$ & $M_{w} / M_{n}$ & $N_{\mathrm{b}}^{\mathrm{c}}$ \\
\hline \multirow[t]{2}{*}{ MDMS-1 } & $\mathrm{Bz}$ & 83.0 & 81.0 & 7.80 & 46.3 & 49.8 & 14.9 & 3.6 & 65.3 \\
\hline & Pht & 89.3 & 92.4 & 12.0 & 58.1 & 48.9 & 20.4 & 4.9 & 87.4 \\
\hline \multirow[t]{2}{*}{ MDMS-3 } & $\mathrm{Bz}$ & 61.1 & 74.6 & 1.68 & 59.8 & 44.3 & 10.6 & 2.1 & 4.4 \\
\hline & Pht & 72.6 & 87.7 & 2.60 & 69.8 & 45.3 & 5.7 . & 2.1 & 2.4 \\
\hline
\end{tabular}

a Copolymerization data at $24 \mathrm{~h}$.

b Instantaneous feed compositions.

c Number of grafts per molecule.

Table V. Copolymerization of MDMS-3 with MMA in benzene ${ }^{a}$

\begin{tabular}{|c|c|c|c|c|c|c|c|c|}
\hline \multirow{2}{*}{$\begin{array}{l}\text { React. } \\
\text { time/h }\end{array}$} & \multicolumn{2}{|c|}{ Conversion $/ \%$} & \multicolumn{2}{|c|}{ MDMS- $3^{\mathrm{b}}$} & \multicolumn{4}{|c|}{ Copolymerization product } \\
\hline & MDMS-1 & MMA & $\mathrm{mol} \%$ & $w t \%$ & MDMS-3 (wt $\%)$ & $M_{w}\left(10^{5}\right)$ & $M_{w} / M_{n}$ & $N_{\mathrm{b}}^{\mathrm{c}}$ \\
\hline 1 & 1.9 & 7.2 & 1.18 & 50.8 & 40.3 & 1.14 & 1.35 & 4.3 \\
\hline 2 & 14.7 & 16.8 & 1.22 & 51.8 & 46.8 & 0.86 & 1.56 & 3.7 \\
\hline 3 & 13.4 & 20.7 & 1.22 & 51.8 & 37.0 & 1.05 & 1.52 & 3.6 \\
\hline 5 & 20.4 & 29.7 & 1.26 & 52.6 & 47.4 & 1.04 & 1.84 & 4.6 \\
\hline 8 & 28.7 & 40.6 & 1.27 & 52.7 & 37.7 & 1.05 & 1.80 & 3.7 \\
\hline 12 & 35.5 & 52.6 & 1.55 & 57.8 & 38.6 & 1.18 & 2.01 & 4.2 \\
\hline 24 & 61.1 & 74.6 & 1.68 & 59.8 & 44.3 & 1.06 & 2.07 & 4.4 \\
\hline 48 & 78.4 & 89.7 & 2.28 & 66.9 & 46.0 & 1.13 & 2.48 & 4.8 \\
\hline
\end{tabular}

${ }^{\text {a }}$ Copolymerizations were carried out with $\mathrm{AIBN}$ at $60^{\circ} \mathrm{C}$.

b Instantaneous feed composition of MDMS-3. $M_{w}=10750$.

c Number of graft segments per molecule. 
conversion curves with $r_{2}=1.0$. It is seen from the figure that the copolymerization data of MDMS- 1 in both $\mathrm{Bz}$ and Pht scatter around the $r_{1}=1.0$ line. This means that the reactivity of the polymerizable end group of the macromonomer is a predominant factor in determining the copolymerization behavior of the macromonomer and other effects such as the incompatibility effect between the macromonomer and propagating comonomer chain which is minor as in the case of the MSt-
MMA-Bz system. The instantaneous mole fraction versus total monomer conversion curves calculated with $r_{2}=0.5$ using eq 2 is also shown in Figure 5 (broken line). The mole fraction of the macromonomer in the copolymerization system is about ten times larger than the MSt system. However, the difference between the curves with $r_{2}=1.0$ and with $r_{2}=0.5$ is not large.

In contrast to MDMS-1, the instantaneous feed compositions of the macromonomer

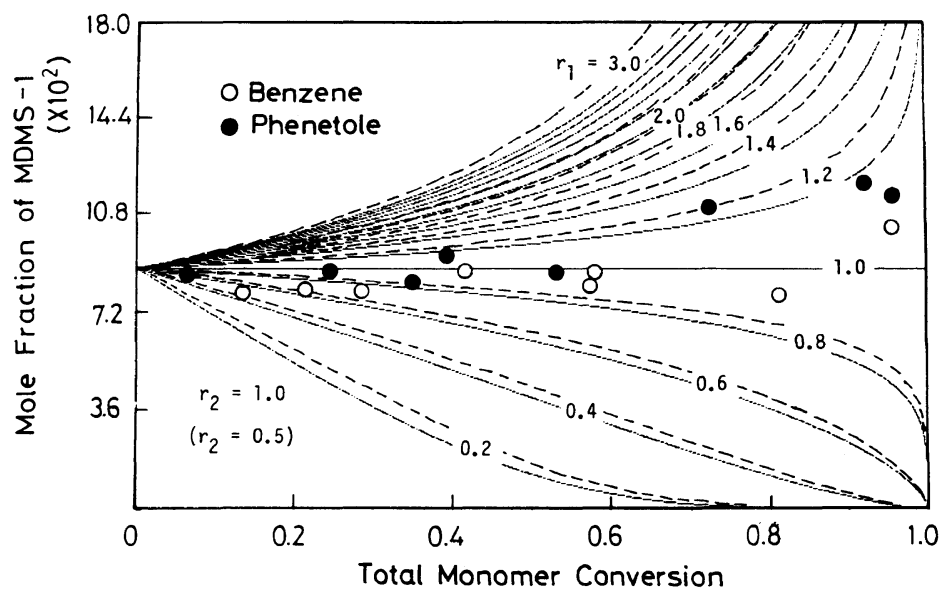

Figure 5. Plots of the experimental instantaneous mol fraction of MDMS-1 on calculated instantaneous mol fraction versus total monomer conversion curves. The solid curves were calculated with $r_{2}=1.0$ using eq 3 , while the broken curves were calculated with $r_{2}=0.5$ using eq 2 .

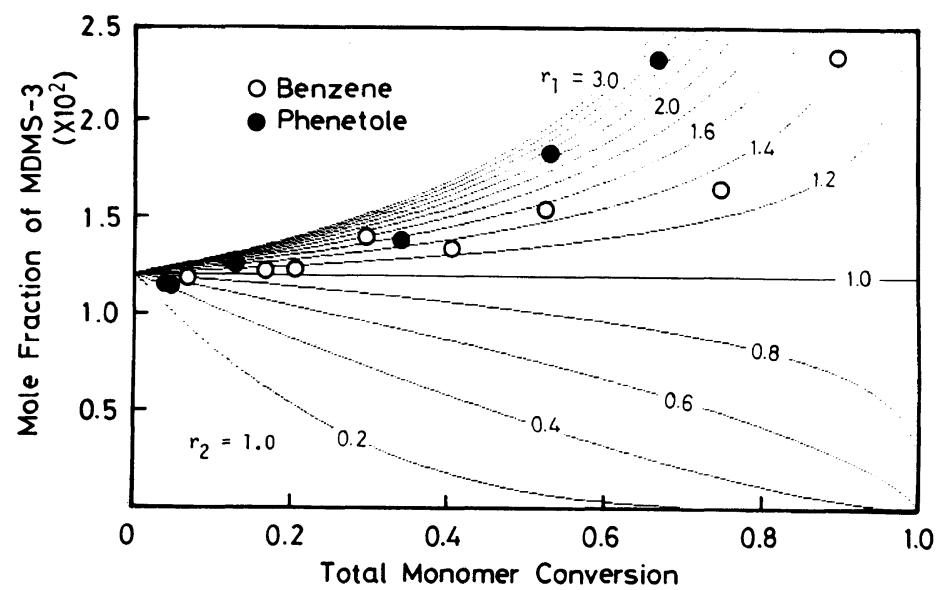

Figure 6. Plots of the experimental instantaneous mol fraction of MDMS-3 on calculated instantaneous mol fraction versus total monomer conversion curves. Curves in the figure were calculated with $r_{2}=1.0$ by using eq 3 . 
MDMS-3, the $M_{n}$ of which is 8670 , in both Bz and $\mathrm{Pht}$ increased with conversion and were higher than those of the feed composition. Accordingly, the compositions of macromonomer in the products are lower than the feed compositions in both solvent.

Figure 6 shows plots of the copolymerization data of MDMS-3 in both Bz and Pht on the calculated instantaneous mole fraction versus total monomer conversion curves with $r_{2}=1.0$. It is seen in the figure that the experimental data in $\mathrm{Bz}$ as well as those in Pht deviate from the $r_{1}=1.0$ line and go to higher values, although the deviation in $\mathrm{Bz}$ is smaller than in Pht. This indicates that the copolymerization reactivity of MDMS-3 estimated from $1 / r_{1}$ is lower than that of the corresponding small monomer in both $\mathrm{Bz}$ and $\mathrm{Pht}$. This tendency is greater in Pht (heterogeneous system) than in $\mathrm{Bz}$ (homogeneous system). Figure 6 shows that the reactivity of MDMS-3 is slightly but lower than the corresponding small monomer in transparent homogeneous system. In other words, in the case of MDMS3 , the reactivity of the polymerizable end group alone is not a predominant factor even in a homogeneous system.

Copolymerization under Transparent Condition

In this section, we discuss how the copolym- erization reactivity of macromonomers is influenced by the incompatibility effect between unlike polymer species under transparent and homogeneous conditions. The influence of the incompatibility or repulsive interaction between the macromonomer and propagating comonomer chain on the reactivity of macromonomer can be interpreted by the degree of interpenetration of these polymer species in the reaction media. That is, if a macromonomer cannot interpenetrate sufficiently the propagating comonomer chain to bring its end group near the radical site due to the incompatibility effect, a decrease in the reactivity of the macromonomer may be observed compared to that of the small monomer corresponding to the polymerizable end group. In other words, if the copolymerization reactivity of a macromonomer is equal to that of the corresponding small monomer, then the macromonomer chain should extensively interpenetrate the propagating comonomer chain. Because, in that case, the distribution of the polymerizable end group must be homogeneous microscopic scale as in the case of small monomers.

In order to clarify the effect, we consider at first a copolymerization system consist of only of macromonomers, the propagating comonomer chains having the same molecular weight

Table VI. Copolymerizations of macromonomers in benzene

\begin{tabular}{|c|c|c|c|c|c|c|}
\hline \multirow{2}{*}{ System } & \multicolumn{2}{|c|}{ Macromonomer } & \multirow{2}{*}{$C^{\mathrm{t}} / \mathrm{g} \mathrm{ml}^{-1}$} & \multirow{2}{*}{$C^{* a}$} & \multirow{2}{*}{$C^{\prime} / C^{*}$} & \multirow{2}{*}{ Appearance } \\
\hline & $M_{w}$ & $D_{\mathrm{p}}$ & & & & \\
\hline MSt & 13100 & 122 & 0.310 & 0.162 & 1.914 & transparent \\
\hline MDMS-1 & 1140 & 11 & 0.241 & 1.768 & 0.136 & transparent \\
\hline MDMS-3 & 10750 & 143 & 0.251 & 0.279 & 0.899 & transparent \\
\hline
\end{tabular}

a Overlap thresholds $C^{*}$ were calculated from the geometric mean of $C_{i}^{*}$;

$$
C_{i}^{*}=\frac{3 M_{w}}{4 \pi\left\langle R_{\mathrm{g}}\right\rangle_{i}^{3 / 2} N_{\mathrm{A}}}
$$

$\left\langle R_{\mathrm{g}}{ }^{2}\right\rangle=1.38 \times 10^{-18} M_{w}{ }^{1.19}\left(\mathrm{~cm}^{2}\right)$ for PSt in benzene $\left(25^{\circ} \mathrm{C}\right)$,

$\left\langle R_{\mathrm{g}}{ }^{2}\right\rangle=2.97 \times 10^{-19} M_{w}{ }^{1.32}\left(\mathrm{~cm}^{2}\right)$ for PDMS in toluene $\left(22^{\circ} \mathrm{C}\right)$,

$\left\langle R_{\mathrm{g}}^{2}\right\rangle=1.13 \times 10^{-18} M_{w}{ }^{1.194}\left(\mathrm{~cm}^{2}\right)$ for PMMA in benzene $\left(30^{\circ} \mathrm{C}\right)$.

b Appearance after copolymerization. 
as the macromonomer and a good solvent. Under this simplification, we introduce the overlap concentration $C^{*}$ using the following relations.

$$
C_{i}^{*}=3 M_{w} / 4 \pi\left\langle R_{\mathrm{g}}^{2}\right\rangle_{i}^{3 / 2} N_{\mathrm{A}} \quad\left(\mathrm{g} \mathrm{ml}^{-1}\right)
$$

where $C_{i}^{*}$ and $\left\langle R_{\mathrm{g}}{ }^{2}\right\rangle_{i}$ are the overlap concentration and mean square radius of gyration of $i$-polymer species, respectively, and $N_{\mathrm{A}}$ is avogadoro's number. $\left\langle R_{\mathrm{g}}{ }^{2}\right\rangle_{i}$ values in $\mathrm{cm}^{2}$ are given by ${ }^{46-48}$ :

$$
\begin{aligned}
& \left\langle R_{\mathrm{g}}{ }^{2}\right\rangle=1.38 \times 10^{-18} M_{w}{ }^{1.19} \\
& \quad\left(\text { for PSt in benzene at } 25^{\circ} \mathrm{C}\right) \\
& \left\langle R_{\mathrm{g}}{ }^{2}\right\rangle=2.97 \times 10^{-19} M_{w}{ }^{1.32} \\
& \quad\left(\text { for PDMS in toluene at } 22^{\circ}\right) \\
& \left\langle R_{\mathrm{g}}{ }^{2}\right\rangle=1.13 \times 10^{-18} M_{w}{ }^{1.194}
\end{aligned}
$$

(for PMMA in benzene at $30^{\circ} \mathrm{C}$ )

Then, the overlap concentration $C^{*}$ of the copolymerization system can be defined by the geometric mean of each value neglecting the temperature effect, and is shown in Table VI. In the polymer(1)-polymer(2)-solvent(3) ternary system of the symmetrical case $\left(\chi_{13}=\chi_{23}\right.$, $N_{1}=N_{2}=N$ ), the critical concentration $C^{\text {crit }}$ for the phase separation is related to the segregation factor $\chi_{12}$ and the overlap concentration $C^{*}$ as follows ${ }^{49}$ :

i) in the case of good solvent and strong segregation factor

$$
C^{\mathrm{crit}} \simeq C^{*} \sim N^{-4 / 5}
$$

ii) in the case of a good solvent and weak segregation factor

$$
C^{\text {crit }} \sim\left(N \chi_{12}\right)^{-4 / 5}
$$

When a system has a good solvent and strong segregation factor, demixing or phase separation will soon take place as $C^{\mathrm{t}}$ exceeds $C^{*}$ due to the strong segregation factor. On the other hand, when the system has a good solvent and weak segregation factor, $C^{t}$ of the ternary system can still increases, keeping the system homogeneous (single phase) as $C^{\mathbf{t}}$ exceed $C^{*}$ because $\chi_{12}$ is not strong enough to induce segregation. Thus, the $C^{\text {crit }}$ of this system is greater than $C^{*}$. It is seen from the Table VI that MDMS-PMMA-Bz system in this study corresponds to the case (i), while MSt-PMMA-Bz system corresponds to the case (ii).

According to Flory-Huggins-Scott theory, the free energy of mixing and critical conditions in the polymer-polymer-solvent ternary system are given by ${ }^{32,50}$

$$
\begin{aligned}
& \Delta G_{\text {mix }}= R T V / V_{3}\left[\phi_{3} \ln \phi_{3}+\left(\phi_{1} / N_{1}\right) \ln \phi_{1}\right. \\
&+\left(\phi_{2} / N_{2}\right) \ln \phi_{2}+\chi_{12} \phi_{1} \phi_{2} \\
&\left.+\chi_{13} \phi_{1} \phi_{3}+\chi_{23} \phi_{2} \phi_{3}\right] \\
&\left(\partial^{2} \Delta G_{\text {mix }} / \partial \phi_{1}{ }^{2}\right)_{\mathrm{T}, \mathrm{P}}=\left(\partial^{3} \Delta G_{\text {mix }} / \partial \phi_{1}{ }^{3}\right)_{\mathrm{T}, \mathrm{P}}=0
\end{aligned}
$$

For the symmetrical case, the binodal condition does not depend on interaction between the polymer and solvent but only on the segregation factor between polymer-1 and polymer-2, $\chi_{12}$, so that the phase behavior can be described with an effective Flory-Huggins $\chi$-prameter defined by

$$
\chi_{12}^{\text {eff }}=\chi_{12}\left(1-\phi_{3}\right)
$$

Table VII. Estimation of the effective $\chi_{\mathrm{AB}}$ and segment length $N_{\mathrm{p}}$ for partial interpenetration

\begin{tabular}{crlccc}
\hline Macromonomer & $D_{\mathrm{p}}$ & $C^{\mathrm{t}}$ & $\phi$ & $\chi_{\mathrm{AB}}^{\text {eff }}$ & $N_{\mathrm{p}}$ \\
\hline MSt & 122 & $C^{\mathrm{t}}>C^{*}$ & $0.237^{\mathrm{a}}$ & $0.0063-0.0142$ & $70-159$ \\
MDMS-1 & 11 & $C^{\mathrm{t}}<C^{*}$ & $0.734^{\mathrm{b}}$ & $0.380-0.510$ & $2-3$ \\
MDMS-3 & 143 & $C^{\mathrm{t}}<C^{*}$ & $0.253^{\mathrm{b}}$ & $0.131-0.176$ & $6-8$ \\
\hline
\end{tabular}

a Overall volume fraction of polymer segments in the copolymerization system.

b Volume fraction of polymer segments in the macromonomer coils assuming polymer concentration in the coil equals to $C^{*}$. 

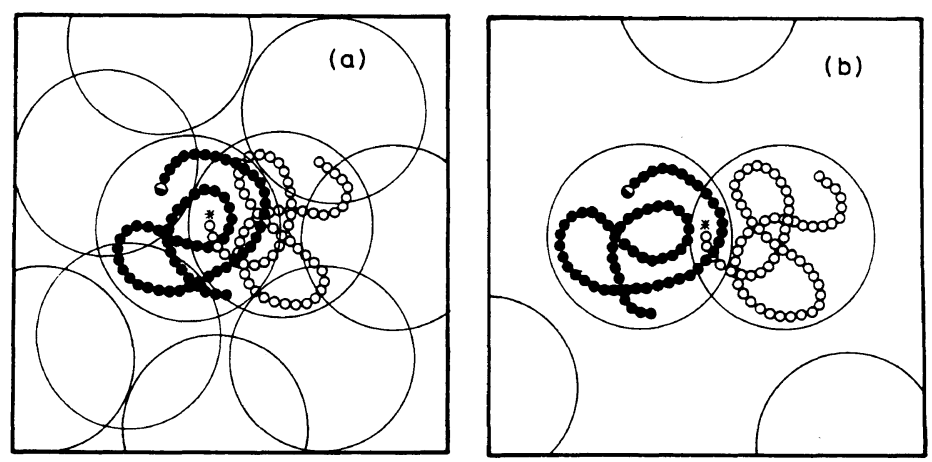

Figure 7. Schematic representation of the interpenetration of the macromonomer and propagating comonomer chain in reaction media: (a), MSt/MMA/Bz; (b) MDMS-3/MMA/Bz.

Furthermore, a partial segment of each polymer having a degree of polymerization less than $N_{\mathrm{p}}<1 / \chi_{12}^{\text {eff }}$ can be compatible even when all the polymer chains are incompatible with each other. ${ }^{17}$ These $\chi_{12}^{\text {eff }}$ and $N_{\mathrm{p}}$ values in our copolymerization system are shown in Table VII using $\delta_{\mathrm{PSt}}=8.9-9.1, \quad \delta_{\mathrm{PDMS}}=7.3-7.6$, $\delta_{\text {PMMA }}=9.5,{ }^{40}$ where $D_{\mathrm{p}}$ in the table is the degree of polymerization of the macromonomer and $\phi$ is the volume fraction of the polymer segment. To calculate $\phi$ in the table, the overall volume fraction of the polymer segment throughout the reaction media was used when the total monomer concentration was greater than $C^{*}$, while the volume fraction of the polymer segment in the macromonomer coil was used when $C^{t}$ was less than $C^{*}$.

By comparison with the calculated $N_{\mathrm{p}}$ values and $D_{\mathrm{p}}$ of macromonomer in Table VII, it can be seen that almost the whole macromonomer chain is compatible with the propagating comonomer chain in the MSt-MMA system. In other words, the macromonomer chain can extensively interpenetrate the coil of the propagating comonomer chain from an incompatibility point of view. On the other hand, in the MDMS copolymerization system, only a small part of the macromonomer chain can interpenetrate the propagating comonomer chain. In this case, the concentration of the polymerizable end group of macromonomers around the propagating radical sites becomes lower than that in the absence of the incompatibility effect; consequently, the propagating rate for a propagating comonomer radical adding macromonomer becomes lower. This situation is schematically shown in Figure 7. It is seen from Figure 5 that the reactivity of MDMS- 1 is almost the same as that of the small monomer. This is probably due to the small size of MDMS-1. When the macromonomer is not large enough to make a random coil, the end group can always approach and contact the propagating radicals without sufficient interpenetration. In that case the incompatibility effect might not be important. When the molecular weight of macromonomer increases enough to make a random coil, the restriction of interpenetration of an unlike polymer species by incompatibility effect and also excluded volume effect influences the reactivity of the macromonomer. The degree of interpenetration in Table VII can reasonably explain the copolymerization data in this study. This also might explain the molecular weight dependent copolymerization reactivity of macromonomers reported in the literature. $^{12-14}$ It should be mentioned that the degree of interpenetration also depends upon $C^{\mathbf{L}}$, since the interpenetration is also related to the excluded volume effect or osmotic effect when $C^{t}$ is below $C^{*}$ even in the absence of incompatibility effect. ${ }^{22-24}$ However, it is difficult at present to draw a clear picture of the 
copolymerization behavior of macromonomers on the basis of all of these effects. For further understanding of these effects, a study of the copolymerization behavior between unlike macromonomers might be better and a much simpler system. Furthermore, evaluation of the chemical composition distribution is also important and desirable to understand the copolymerization behavior in more details. ${ }^{51-52}$

\section{CONCLUSIONS}

It has been shown in this study that the relative copolymerization reactivity of macromonomer in the system of St-macromonomer with MMA in $\mathrm{Bz}$ is almost the same as that of the small monomer corresponding to the polymerizable end group. In this case, the effect of thermodynamic repulsive interaction between macromonomers and the propagating comonomer chains on the reactivity is not important and negligible. On the other hand, decrease in the copolymerization reactivity of macromonomer to some extent was observed in the copolymerization system of the high molecular weight DMS-macromonomer with MMA in $\mathrm{Bz}$ even under a transparent solution condition. These observations are well described in terms of the difference in the degree of interpenetration of unlike polymer reaction species due to the difference in the effect of thermodynamic repulsive interaction between the macromonomer and propagating comonomer chain. In the case of copolymerizations in the preferential solvents, the copolymerization system becomes translucent and opaque as copolymerization proceeds, resulting in production of polymer particles of considerably uniform size. Appreciable decrease in the relative copolymerization reactivity of macromonomer was observed due to much decrease in the interpenetration of unlike polymer reaction species.

Acknowledgement. This research was sup- ported in part by a Grant-in-Aid for Scientific Research (No. 63750866) from the Ministry of Education, Science, and Culture, Japan. The authors are indebted to Chisso Co., Ltd. for supplying MDMS macromonomers. The authors are also indebted to Maxell Co., Ltd. for taking the electron microphotographs.

\section{REFERENCES}

1. Y. Yamashita, J. Appl. Polym. Sci., Appl. Polym. Symp., 36, 193 (1981).

2. Y. Tsukahara, H-C. Tsai, Y. Yamashita, and Y. Muroga, Polym. J., 19, 1033 (1987); Y. Tsukahara, K. Ito, H-C. Tsai, and Y. Yamashita, J. Polym. Sci., Polym. Chem., in press.

3. Y. Tsukahara, K. Kohno, and Y. Yamashita, Nippon Kagaku Kaishi, 1020 (1985).

4. Y. Tsukahara, K. Kohno, and Y. Yamashita, in "Current Topics in Polymer Science," Vol. II, R. M. Ottenbrite, L. A. Utracki, and S. Inoue, Ed., Hanser Publisher, Munich Vienna, New York, 1987, p 333.

5. Y. Yamashita and Y. Tsukahara, in "Modification of Polymers," C. Carraher and J. Moore, Ed., Plenum Press, New York, N. Y., 1983, p 131.

6. Y. Kawakami, Y. Miki, T. Tsuda, R. A. N. Murthy, and Y. Yamashita, Polym. J., 14, 913 (1982).

7. Y. Chujo, T. Shishino, Y. Tsukahara, and Y. Yamashita, Polym. J., 17, 133 (1985).

8. K. Ito, N. Usami, and Y. Yamashita, Macromolecules, 13, 216 (1980).

9. R. Asami, M. Takaki, K. Kita, and E. Asakura, Polym. Bull., 2, 713 (1979); R. Asami, M. Takaki, K. Kyuda, and N. Sukenaga, Polym. J., 15, 261 (1983); M. Takaki, R. Asami, S. Tanaka, H. Hayashi, and T. Hogen-Esch, Macromolecules, 12, 2900 (1986).

10. T. Nishimura, M. Maeda, Y. Nitadori, and T. Tsuruta, Makromol. Chem., Rapid Commun., 180, 1877 (1979); Y. Nagasaki and T. Tsuruta, Makromol. Chem., 187, 1583 (1986).

11. P. F. Rempp and E. Franta, Adv. Polym. Sci., 58, 1 (1984); J. Sierra-Vagas and E. Franta, Makromol. Chem., 182, 2603 (1981).

12. K. Ito, H. Tsuchida, A. Hayashi, T. Kitano, E. Yamada, and T. Matsumoto, Polym. J., 15, 827 (1985).

13. K. Ito, H. Tsuchida, and T. Kitano, Polym. Bull., 15, 425 (1986).

14. G. G. Cameron and M. S. Chisholm, Polymer, 26, 437 (1985); G. G. Cameron and M. S. Chisholm, ibid., 27, 1420 (1986).

15. G. O. Schulz and R. J. Milkovich, J. Polym. Sci., Polym. Chem. Ed., 22, 1633 (1984).

16. J. P. Kennedy and C. Y. Lo, Polym. Bull., 8, 63 (1.982); J. P. Kennedy and C. Y. Lo, ibid., 13, 343 
(1985)

17. Y. Tsukahara, M. Tanaka, and Y. Yamashita, Polym. J., 19, 1121 (1987).

18. Y. Tsukahara and Y. Yamashita, IUPAC 32nd Inter. Symp. on Macromolecules in Kyoto, 1988, p 452.

19. Y. Tsukahara, K. Mizuno, A. Segawa, and Y. Yamashita, Macromolecules, in press.

20. T. Tulig and M. Tirrell, Macromolecules, 14, 1501 (1981).

21. P. G. de Gennes, J. Chem. Phys., 76, 3316, 3322 (1982).

22. K. Horie, I. Mita, and H. Kambe, Polym. J., 4, 341 (1973); K. Horie and I. Mita, Macromolecules, 11, 1175 (1978).

23. I. Mita and K. Horie, J. Macromol. Sci.-Rev., Macromol. Chem. Phys., C27, 91 (1987).

24. H. Morawetz, J. R. Cho, and P. J. Gans, Mcromolecules, 6, 624 (1973).

25. H. Iwata and Y. Ikada, Makromol. Chem., 181, 517 (1980).

26. M. Smoluchowski, Z. Phys. Chem., 92, 129 (1918).

27. E. Trommsdorf, H. Kohle, and P. Lagally, Makromol. Chem., 1, 169 (1948).

28. D. T. Turner, Macromolecules, 10, 221, 226, 231 (1977).

29. K. F. O'Driscoll and H. K. Mahabadi, J. Polym. Sci., Polym. Chem. Ed., 14, 869 (1976); K. F. O'Driscoll and H. K. Mahabadi, ibid., 15, 283 (1977).

30. W. A. Ludwico and S. L. Rosen, J. Appl. Polym. Sci., 19, 757 (1975); W. A. Ludwico and S. L. Rosen, $J$. Polym. Sci., Polym. Chem., 14, 2121 (1976).

31. G. Riess, C. Beslin, J. L. Locatelli, and J. L. Refregier, in "Polymer Alloys," D. Klempner and K. C. Frisch, Ed., Plenum Press, New York, N. Y., 1977, p 337.

32. D. R. Paul and S. Newman, "Polymer Blends," Vols 1 and 2, Academic Press, New York, N. Y., 1978.

33. T. Inoue, T. Soen, T. Hashimoto, and H. Kawai, Macromolecules, 3, 87 (1970).

34. T. Hashimoto, M. Shibayama, and H. Kawai, Macromolecules, 13, 1237 (1980).

35. T. Hashimoto, Y. Tsukahara, and H. Kawai, J.
Polym. Sci., Lett. Ed., 18, 585 (1980); T. Hashimoto, Y. Tsukahara, and H. Kawai, Macromolecules, 14, 708 (1981).

36. T. Kotaka, Ed., "Polymer Alloys," Tokyo Kagaku Dohjin, Tokyo, 1981; T. Kotaka, H. Ohnuma, and $\mathrm{H}$. Inagaki, in "Colloid and Morphological Behavior of Block and Graft Copolymers," G. E. Molau, Ed., Plenum Press, New York, N. Y., 1971.

37. T. Fukuda, M. Nagata, and H. Inagaki, Macromolecules, 19, 1411 (1986); T. Fukuda, M. Nagata, and H. Inagaki, ibid., 20, 654 (1987).

38. P. J. Flory, L. Mandelkern, J. B. Kinsinger, and W. B. Schultz, J. Am. Chem. Soc., 74, 3364 (1952).

39. N. Kuwahara and M. Kaneko, Makromol. Chem., 82, 205 (1965).

40. J. Brandrup and E. H. Immergut, Ed., "Polymer Handbook," 2nd ed, John Wiley \& Sons, New York, N. Y., 1975.

41. G. Odian, "Principles of Polymerization," 2nd ed, John Wiley \& Sons, New York, N. Y., 1981.

42. I. Skeist, J. Am. Chem. Soc., 68, 1781 (1946).

43. I. H. Spinner, B. C. Lu, and W. F. Gaydon, J. Am. Chem. Soc., 77, 2198 (1955).

44. V. E. Meyer and G. G. Lowry, J. Polym. Sci., A, 3, 2843 (1965).

45. K. E. J. Barrett and H. R. Thomas, in "Dispersion Polymerization in Organic Media,” K. E. J. Barrett, Ed., John-Wiley \& Sons, London, New York, 1975.

46. I. Noda, Y. Higo, T. Ueno, and T. Fujimoto, Macromolecules, 17, 1055 (1984).

47. L. O. Kaddour and Cl. Strazielle, Polymer, 28, 459 (1987).

48. N. Numasawa, K. Kuwamoto, and T. Nose, Macromolecules, 19, 2593 (1986).

49. P. G. de Gennes, "Scaling Concepts in Polymer Physics," Cornell University Press, Ithaca, N. Y., 1979, Chapter 4.

50. R. L. Scott, J. Chem. Phys., 17, 279 (1949).

51. J. Stejskal, P. Kratochvil, and A. D. Jenkiins, Macromolecules, 20, 181 (1987).

52. Y. Tsukahara, M. Oguri, Y. Yamashita, and S. Teramachi, to be submitted. 